\title{
Nutritional Benchmarking: A Top Priority
}

\author{
Massimiliano Sansone*, Andrea Sansone, Elena Gangitano, Mariagrazia Romano, Silvia Seraceno and Francesco \\ Romanelli \\ Department of Experimental Medicine, Sapienza - University of Rome, Italy
}

Received: 無: October 05, 2018; Published: 做: October 15, 2018

*Corresponding author: Massimiliano Sansone, Department of Experimental Medicine, Section of Medical Pathophysiology, Food Science and Endocrinology, Sapienza - University of Rome, Rome, Italy

Abbreviations: CHO: Carbohydrate Ratio: CR: Caloric Restriction: IGF: Insulin-Growth Factor: AMPK: Activated Protein Kinase: PPAR $\gamma$ : Peroxisome Proliferator-Activated Receptor- $\gamma$ : MTOR: Mammalian Target of Rapamycin: PGC: Proliferator-Activated Receptor Coactivator: KD: Ketogenic Diet

\section{Introduction}

\section{Funding Disclosures}

In the world of nutritional science, more and more studies have been performing for the last years with interesting results; nevertheless, at the moment outcomes of these studies do not provide consistent benchmarks that may use to build a nutritional plan or to lead further researches. Contrasting evidence represents an important drawback in this field creating a confusing background; indeed, these conflictual aspects concern the majority of topics in nutritional science. When attention is focused on total daily caloric intake, protein daily intake and daily carbohydrate (CHO)/ fat ratio, it is possible to observe a great discordance of evidence. As regards total daily caloric intake, recent evidence shows that a daily reduction of $20-30 \%$ of caloric intake may significantly increase life span; in particular, this increased longevity seems to be confirmed in animal models whereas in humans long-term studies are not present at the moment to confirm this hypothesis [1-3]. Considering that actual dietary guidelines suggest approximately $2000 \mathrm{kcal} /$ die diet for a man of $\sim 70 \mathrm{~kg}$, a reduction of $20-30 \%$ of daily caloric intake would be represented by a nutritional plan of $\sim 1400 \mathrm{kcal} / \mathrm{d}$ for a man of $\sim 70 \mathrm{~kg}[4-6]$.

Several mechanisms have been proposed to explain this evidence, and the reduction of mitogen stimuli caused at least partly by decreased hormonal levels, such as insulin, insulin-growth factor 1 (IGF-1), and testosterone appears to play a pivotal role [78]. This decrease in hormonal production affects also negatively the activity of mitogen pathways, such as mammalian target of rapamycin (mTOR) signalling pathway activated by insulin and FOXO a key checkpoint gene in the insulin-IGF-1 signaling pathway upregulated by CR[9]. Furthermore, caloric restriction (CR) seems to mimic physical exercise activating biological pathways which are stimulated by physical exercise, such as AMP-activated protein kinase (AMPK) signalling pathways, and to increase sirtuin levels [10]. In particular, the ability of sirtuins to influence metabolism and potentially life span is believed to revolve around the ability of sirtuin family members to function as protein deacetylases. Evidence suggests that mitochondrial biogenesis is regulated at least in part by proliferator-activated receptor coactivator- $1 \alpha$ (PGC-1 $\alpha$ ), a transcriptional coactivator of peroxisome proliferatoractivated receptor- $\gamma$ (PPAR $\gamma$ ) as well as other transcription factors [11]. It was therefore of considerable interest when it was shown that PGC- $1 \alpha$ was in fact a deacetylation target of Sirt1 and that mechanism regulated PGC-1 $\alpha$ activity [12].

On the other side, in sport nutrition evidence suggests that a high daily caloric intake has ergogenic properties increasing skeletal muscle glycogen replenishment and anabolic response to training induced stimuli in endurance activities [13-14]. In this framework a total daily intake of $\sim 4000-6000 \mathrm{kcal}$ is not uncommon taking into account that 5-6 hours of endurance training may cost $~ 3500$ $4200 \mathrm{kcal}$ not including rest metabolism rate which may account for $1600-1800 \mathrm{kcal} /$ die to sustain resting metabolic processes in a $70 \mathrm{~kg}$ man [15]. Indeed, an intake of $\sim 7-12 \mathrm{~g} / \mathrm{kg} / \mathrm{CHO} / \mathrm{d}$ is frequently reported among endurance athletes, accompanied by an intake of $\sim 1.7-2 \mathrm{~g} /$ protein/d to sustain anabolic processes with the rest of daily caloric intake coming from fat intake [16-18]. Indeed, both endurance and resistance athletes try to maximize anabolic pathways and skeletal muscle synthesis by ingesting a high daily amount of protein and, in some cases, administering illegal performance enhancing drugs, such as insulin, IGF-1, growth hormone and testosterone [19]. These ways are clearly in contrast with what has been proposed by CR diet, and it seems that targets of maximizing physical performance and increasing life span could not be pursued at the same time. A similar conflict may be observed even when daily protein intake is considered; opposite evidence appears to suggest significant metabolic improvements brought about by both high and low protein diet [20-21].

Nevertheless, a similar situation can be observed when daily fat intake is concerned; indeed, in the last years a great number of studies support the properties of ketogenic diet (KD) to improve 
metabolic parameters and body composition [22-27]. KD is generally characterized by a total carbohydrate intake of less than $50 \mathrm{~g} / \mathrm{d}$ and a moderate protein intake of approximately $1.5 \mathrm{~g} /$ $\mathrm{kg} / \mathrm{d}$ to induce ketogenesis. Indeed, despite no standard definition exists to define the ideal range of carbohydrate intake to achieve ketosis because of individual variability, a carbohydrate daily intake of $0.5 \mathrm{~g} / \mathrm{kg} / \mathrm{d}$ may represent an accurate assessment [2829]. Daily protein intake should range from 1.76 to $2.2 \mathrm{~g} / \mathrm{kg}$ lean mass $/ \mathrm{d}$ or $1.2-1.7 \mathrm{~g} / \mathrm{kg}$ body weight $/ \mathrm{d}$, and the remaining calories should come from fat, covering $70-80 \%$ of daily energy intake [30-31]. This low intake of CHO is clearly in contrast with daily intake recommended by nutritional guidelines; generally the ratio of macronutrients proposed by KD is opposite compared to the ratio suggested by the majority of nutritional guidelines [32-34]. Notwithstanding, KD appears to be a promising diet even though further evidence is required to sustain metabolic benefits of KD. Finally, this brief manuscript highlights the presence of contrasting and confusing evidence in different aspects of nutritional science; further studies are warranted to find significant benchmarks which may lead clinicians and scientists in their activities.

\section{References}

1. Bales CW, Kraus WE (2013) Caloric restriction: implications for human cardiometabolic health. J Cardiopulm Rehabil Prev 33(4): 201-208.

2. Redman LM, Smith SR, Burton JH, Martin CK, Il'yasova D, et al. (2018) Metabolic Slowing and Reduced Oxidative Damage with Sustained Caloric Restriction Support the Rate of Living and Oxidative Damage Theories of Aging. Cell Metab 27(4): 805-815.

3. Civitarese AE, Carling S, Heilbronn LK, Hulver MH, Ukropcova B, et al. (2007) Calorie restriction increases muscle mitochondrial biogenesis in healthy humans. PLoS Med 4(3): e76.

4. Mifflin MD, St Jeor ST, Hill LA, Scott BJ, Daugherty SA, et al. (1990) A new predictive equation for resting energy expenditure in healthy individuals. Am J Clin Nutr 51(2): 241-247.

5. Roza AM, Shizgal HM (1984) The Harris Benedict equation reevaluated: resting energy requirements and the body cell mass. Am J Clin Nutr 40(1): 168-182.

6. Gerrior S, Juan W, Basiotis P (2006) An easy approach to calculating estimated energy requirements. Prev Chronic Dis 3(4): A129.

7. Cangemi R, Friedmann AJ, Holloszy JO, Fontana L (2010) Long-term effects of calorie restriction on serum sex-hormone concentrations in men. Aging Cell 9(2): 236-242.

8. Lee SH, Min KJ (2013) Caloric restriction and its mimetics. BMB Rep 46(4): 181-187.

9. Willcox BJ, Willcox DC (2014) Caloric restriction, caloric restriction mimetics, and healthy aging in Okinawa: controversies and clinical implications. Curr Opin Clin Nutr Metab Care 17(1): 51-58.

10. Canto C, Auwerx J (2011) Calorie restriction: is AMPK a key sensor and effector? Physiology (Bethesda) 26(4): 214-224.

11. Fernandez-Marcos PJ, Auwerx J (2011) Regulation of PGC-1alpha, a nodal regulator of mitochondrial biogenesis. Am J Clin Nutr 93(4): 884s890.

12. Gurd BJ (2011) Deacetylation of PGC-1alpha by SIRT1: importance for skeletal muscle function and exercise-induced mitochondrial biogenesis. Appl Physiol Nutr Metab 36(5): 589-597.

13. Bussau VA, Fairchild TJ, Rao A, Steele P, Fournier PA (2002) Carbohydrate loading in human muscle: an improved 1 day protocol. Eur J Appl Physiol 87(3): 290-295.
14. Walberg-Rankin J (1995) Dietary carbohydrate as an ergogenic aid for prolonged and brief competitions in sport. Int J Sport Nutr Suppl: S1328.

15. Kerksick CM, Arent S, Schoenfeld BJ, Jeffrey R. Stout, Bill Campbell, et al. (2017) International society of sports nutrition position stand: nutrient timing 14(1): 33.

16. Rauch LH, Rodger I, Wilson GR, Belonje JD, Dennis SC, et al. (1995) The effects of carbohydrate loading on muscle glycogen content and cycling performance. Int J Sport Nutr 5(1): 25-36.

17. Burke LM, Cox GR, Culmmings NK, Desbrow B (2001) Guidelines for daily carbohydrate intake: do athletes achieve them? Sports Med 31(4): 267-299.

18. Jager R, Kerksick CM, Campbell BI, Cribb PJ, Wells SD, et al. (2017) International Society of Sports Nutrition Position Stand: protein and exercise. J Int Soc Sports Nutr 14(1): 20.

19. Di Luigi L, Romanelli F, Lenzi A (2005) Androgenic-anabolic steroids abuse in males. J Endocrinol Invest 28(3 Suppl): 81-84.

20. Campbell TC, Chen J (1999) Energy balance: interpretation of data from rural China. Toxicol Sci 52(2 Suppl): 87-94.

21. Cintineo HP, Arent MA, Antonio J, Shawn M (2018) Arent Effects of Protein Supplementation on Performance and Recovery in Resistance and Endurance Training. Front Nutr 5(1): 83.

22. Johnstone AM, Horgan GW, Murison SD, Bremner DM, Lobley GE, et al. (2008) Effects of a high-protein ketogenic diet on hunger, appetite, and weight loss in obese men feeding ad libitum. Am J Clin Nutr 87(1): 44-55.

23. Partsalaki I, Karvela A, Spiliotis BE (2012) Metabolic impact of a ketogenic diet compared to a hypocaloric diet in obese children and adolescents. J Pediatr Endocrinol Metab 25(7-8): 697-704.

24. Ruth MR, Port AM, Shah M, Bourland AC, Istfan NW, et al. (2013) Consuming a hypocaloric high fat low carbohydrate diet for 12 weeks lowers C-reactive protein, and raises serum adiponectin and high density lipoprotein-cholesterol in obese subjects. Metabolism 62(12): 1779-1787.

25. Hu T, Bazzano LA (2014) The low-carbohydrate diet and cardiovascular risk factors: evidence from epidemiologic studies. Nutr Metab Cardiovasc Dis 24(4): 337-343.

26. Hession M, Rolland C, Kulkarni U, Wise A, Broom J (2009) Systematic review of randomized controlled trials of low-carbohydrate vs. low-fat/ low-calorie diets in the management of obesity and its comorbidities. Obes Rev 10(1): 36-50.

27. Saslow LR, Kim S, Daubenmier JJ, Moskowitz JT, Phinney SD, et al. (2014) A randomized pilot trial of a moderate carbohydrate diet compared to a very low carbohydrate diet in overweight or obese individuals with type 2 diabetes mellitus or prediabetes. PLoS One 9(4): e91027.

28. Veech RL (2004) The therapeutic implications of ketone bodies: the effects of ketone bodies in pathological conditions: ketosis, ketogenic diet, redox states, insulin resistance, and mitochondrial metabolism. Prostaglandins Leukot Essent Fatty Acids 70(3): 309-319.

29. Zilberter T, Zilberter Y (2018) Ketogenic Ratio Determines Metabolic Effects of Macronutrients and Prevents Interpretive Bias. Front Nutr 5(1): 75.

30. Miller VJ, Villamena FA, Volek JS (2018) Nutritional Ketosis and Mitohormesis: Potential Implications for Mitochondrial Function and Human Health. J Nutr Metab 2018: 5157645.

31. Paoli A, Rubini A, Volek JS, Grimaldi KA (2013) Beyond weight loss: a review of the therapeutic uses of very-low-carbohydrate (ketogenic) diets. Eur J Clin Nutr 67(8): 789-796.

32. Eckel RH, Jakicic JM, Ard JD, Janet M de Jesus, et al. (2014) 2013 AHA/ ACC guideline on lifestyle management to reduce cardiovascular risk: a report of the American College of Cardiology/American Heart 
Association Task Force on Practice Guidelines. J Am Coll Cardiol 129(25): 2960-2984.

33. Evert AB, Boucher JL, Cypress M, Dunbar SA, Franz MJ, et al. (2014) Nutrition therapy recommendations for the management of adults with diabetes. Diabetes Care 37(Suppl 1): 120-143.

ISSN: 2574-1241

DOI: 10.26717/BJSTR.2018.10.001893

Massimiliano Sansone. Biomed J Sci \& Tech Res

(c) (P) This work is licensed under Creative Commons Attribution 4.0 License

Submission Link: https://biomedres.us/submit-manuscript.php
34. Millen BE, Abrams S, Adams-Campbell L, Cheryl AM Anderson, I Thomas Brenna, et al. (2016) The 2015 Dietary Guidelines Advisory Committee Scientific Report: Development and Major Conclusions 7(3): 438-444.

$\begin{array}{ll}\text { BIOMEDICAL } & \text { Assets of Publishing with us } \\ \text { RESEARCHES } & \text { - Global archiving of articles } \\ \text { - Immediate, unrestricted online access } \\ \text { - Rss: 2574-1241 }\end{array}$

